\author{
Lamia T Rejab \\ BDS, MSc (Lect) \\ Nadiaa H Hasan \\ BDS, MSc ( Lect)
}

Akram A Mohammad

$\mathrm{MSc}, \mathrm{PhD}$ (prof)

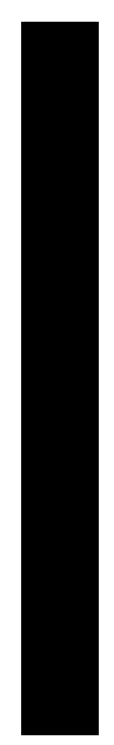
(Reinforcement)

\section{Evaluation of some physical properties
of the copolymerized temporary crown
and bridge auto-cured acrylic resin \\ Evaluation of some physical properties
of the copolymerized temporary crown
and bridge auto-cured acrylic resin \\ Evaluation of some physical properties
of the copolymerized temporary crown
and bridge auto-cured acrylic resin}

\author{
Department of Prosthetic Dentistry \\ College of Dentistry, University of Mosul
}

Department of Chemistry

Collage of Science, University of Mosul

\begin{abstract}
Aims: To evaluate some of the physical properties which are transverse strength, tensile strength, surface hardness, water sorption and solubility of the auto-cured acrylic resin when copolymerized with epoxy resin at two different ratios $10 \%$ and $20 \%$ of its weight and then compared with that of auto-cured alone and heat-cured acrylic resin alone. materials and methods: The tested samples were divided into four groups according to the materials to be used and the samples of each group were subdivided according to the test to be done. The samples were prepared according to ADA Specification No. 12. Statistically analysis of the physical properties was with (ANOVA) and Duncan's multiple range test to determine significant different at $(\mathrm{p} \leq 0.05)$ level of significance, and the mean value of the water sorption and solubility ratios compared with accepted limit of ADA Specification No. 12. Results: The transverse strength, tensile strength and surface hardness in this study showed that there was a highly significant difference between the four tested groups. The result appeared improving of the mechanical properties and decreasing the ratio of water sorption and solubility of the auto-cured acrylic resin and the resin was reinforced when copolymerized at $10 \%$, but the values still not reached that of the heat-cured acrylic resin and they became worse when copolymerized at $20 \%$.

Key words: Acrylic resin, epoxy resin, copolymerization, reinforcement
\end{abstract}

Rejab LT, Hasan NH, Mohammad AA. Evaluation of some physical properties of the copolymerized temporary crown and bridge auto-cured acrylic resin (Reinforcement). Al-Rafidain Dent J. 2007; 7(2): $160-165$.

Received: 27/3/2006

Sent to Referees: $3 / 4 / 2006$

Accepted for Publication: 7/6/2006

\section{INTRODUCTION}

Temporary crown and bridge resins are used to provide immediate coverage following tooth preparation and are cemented into place with temporary cement. ${ }^{(1)}$ Polymethyl methacrylate acrylic resins (PMMA) are the principal materials in fabrication of temporary crown and bridge, these are, essentially, similar to the denture base acrylic resins. ${ }^{(2-4)}$ Polymethyl methacrylate acrylic resin gained wide spread usage due to its ease of use and available in range of shade can be matched with tooth substances. The problems of PMMA are low toughness, low fatigue resistant, premature failure, the material has irritant effect due to residual monomer methylmethacr- ylate (MMA) coupled with significant temperature rise caused by exothermic polymerization reaction, and considerable setting contraction..$^{(1,5)}$

The mechanical properties of the chemically activated (auto-cured) acrylic resin are inferior when compared to heat-cured resin because the degree of polymerizetion achieved is lower so there is a great amount of un-reacted monomer. ${ }^{(6)}$ Efforts made to reinforced multiphase acrylic resin polymer. ${ }^{(7)}$ Improving the physical properties of the polymer can be achieved by alteration of its composition to produce a copolymer. ${ }^{(8,9)}$ A copolymer is formed when two or more different monomers react during polymerization and the process cal- 
led copolymerization. The composition and the properties of the copolymer are defer from original monomer matrix alone. ${ }^{(10,11)}$ Acrylic resin polymer (PMMA) are multiphase in nature typically made from polymer powder and monomer liquid. $^{(1,2)}$ In case of the auto-polymerizing PMMA, liquid contain chemical activator which is an aromatic tertiary amine, and cross linking agent. Powder polymer contain an initiator which is benzyl peroxide which is decomposed by the action of the chemical activator into the reactive species which are a free radical in nature. In case of free radical addition polymerization cross linking agents are invariably difunctional alkenes (glycol dimethacrylate) in which each of the tow double bonds present is able to become polymerized into a separate chain thus affecting linking two chain together. ${ }^{(1,7,9,12)}$

Another resin family of interest to clinical dentistry is an epoxy resin which is the diglycidyl ether of bisphenol-A (DGEBA). These thermosetting resins are viscous, liquid, cured at room temperature by used of reactive intermediate, they have desirable adhesive strength, low curing shrinkage, low temperature, and low pressure and have high strength and curing without evolution of by-product with ease of use. ${ }^{(13,14)}$ Epoxy is used in dentistry as a die material, and the resin of (Bis-GMA ) formula which based upon the(DGEBA) starting material is being used as a pit and fissure sealant and as the matrix for the commonly used composite restorative materials. ${ }^{(15-17)}$ Epoxy resins manufacturing based on two raw materials which are epichlorhydrin and bisphenol. A Reaction of mixture of these two raw materials with a base give a linear epoxy resins. ${ }^{(18)}$ Epoxy resin may be cured by use of reactive intermediate to join the resin chains. The primary cross linking agents are organic bases, tertiary amines $\left(\mathrm{R}_{3} \mathrm{~N}\right.$ : $)$. The epoxy resin molecule is characterized by the reactive oxirane groups which serves as a terminal polymerization points. It is possible to take advantage of the remaining oxirane groups and hydroxyl groups in the linear polymer and form cross-links between polymer chains. ${ }^{(13,14)}$

The purpose of this study to evaluate the transverse strength, tensile strength, surface hardness, water sorption and solubility of the copolymerized auto-cured acrylic resin when mixed with epoxy at two different ratios $10 \%$ and $20 \%$ of weight and then compared with that of auto-cured alone and heat-cured acrylic resin alone.

\section{MATERIALS AND METHODS}

The tested materials used in this study were auto-cured and heat-cured acrylic resins (Major2, prodotti Dentari, Italy ). Auto-cured epoxy resin (EAGLESTAR, USA).

The tested samples were divided into four groups according to the materials to be used as follow, Group I (control group) include auto-cured acrylic resin alone, Group II include auto-cured acrylic resin mixed with $10 \%$ of its weight epoxy, Group III include auto-cured acrylic resin mixed with $20 \%$ of its weight epoxy, Group IV(control group) include heat-cured acrylic resin alone. The samples of each group were subdivided according to the test to be done, 8 samples for each of the transverse strength test, tensile strength test and surface hardness test and 2 samples for water sorption and solubility test. (2,19,20) $^{-}$ So the total number of the samples for each group was 26 and the final total number for the four groups was 104 samples.

The auto and heat-cured acrylic resins were mixed at powder / liquid ratio of $(2.5 / 1)$ by weight. ${ }^{(21)}$ The mixture was left for about 10 minutes at room temperature $\left(21 \pm 1{ }^{\circ} \mathrm{C}\right)$ to reach the required dough stage at which the epoxy resin was mixed with curing agent in a ratio recommended by the manufacturer's instructions and then added to the auto-cured acrylic resin mixture at the two different ratios in Group II and Group III. Samples were prepared by dough molding method with the conventional denture-flasking procedure. Depending on the material being used the resins in Group I, Group II and Group III were bench cured at room temperature $\left(21 \pm 1{ }^{\circ} \mathrm{C}\right)$ for 15 minutes. The heat-cured resin in Group IV was cured in two steps polymerrization, $70{ }^{\circ} \mathrm{C}$ for 30 minutes, then proceed at $100{ }^{\circ} \mathrm{C}$ for 30 minutes in a thermostatically controlled water bath. The prepared samples for transverse strength, tensile strength and surface hardness tests were conditioned at $37{ }^{\circ} \mathrm{C}$ for 48 hours in dist- 
illed water before testing. ${ }^{(22)}$

For the evaluation of the transverse strength and surface hardness tests the samples were prepared with a dimension ( $65 \times 10 \times 2.5 \pm 0.03 \mathrm{~mm}$ ) (length, width and thickness respectively ) according to ADA Specification No. 12. ${ }^{(2,19)}$ The transverse strength was evaluated with a 3 - points bending test machine (Instron testing machine, Clock house, Germany). The surface hardness was evaluated with Rock well hardness tester ( Wolpert, Germany ).

The samples for evaluation the tensile strength were prepared in dumbell-shaped with a dimension of total length $65 \mathrm{~mm}$ of the specimen, $2.5 \mathrm{~mm}$ in thickness, the wi$\mathrm{dth}$ of the specimen at the widest part was
$12.5 \mathrm{~mm}$ and $5 \mathrm{~mm}$ at the narrowest part. ${ }^{(10,20)}$ Textile Tensile Strength Tester (UENOYAMA KIKO Co., Kyoto, Japan) was used for the evaluation.

The samples of the water sorption and solubility were prepared according to the ADA Specification No. 12 as disks with a dimension $(50 \pm 1 \mathrm{~mm}$ in diameter and 0.5 $\pm 0.1 \mathrm{~mm}$ ). Electronic balance ( Mettler PM 460 , Germany ) was used to measure the weight of the disks. The disks were immersed in distilled water for 7 days. The weight of the disks was measured before and after immersion. The ratios of the water sorption and solubility was calculated with the following equations ${ }^{(2)}$ :

$$
\begin{aligned}
& \text { Water sorption }=\frac{\text { weight after immersion }(\mathrm{mg})-\text { weight before immersion }(\mathrm{mg})}{\left(\mathrm{mg} / \mathrm{cm}^{2}\right)} \\
& \text { surface area }(\mathrm{cm})^{2}
\end{aligned}
$$

After the final weighing the disks dried (conditioned) in desiccator containing silica gel at $37 \pm 2^{\circ} \mathrm{C}$ for 24 hours then weighed. The soluble matter lost during imm- ersion which represent ratio of water solubility was determined as follow for each disk :

$$
\begin{gathered}
\text { Water solubility } \\
\left(\mathrm{mg} / \mathrm{cm}^{2}\right)
\end{gathered}=\frac{\text { weight before immersion }(\mathrm{mg})-\text { dried weight }(\mathrm{mg})}{\text { surface area }(\mathrm{cm})^{2}}
$$

The values of the water sorption and solubility ratios for the disks were determined and recorded.

Statistically analysis the mean values and standard deviation of the collected data of the transverse strength, tensile strength and surface hardness tests were calculated and the results were compared with one-way analysis of variance (ANOVA). This was followed by Duncan's multiple range test to determine significant differe$\mathrm{nt}$ at ( $\mathrm{p} \leq 0.05$ ) level of significance, and the mean value of the water sorption and solubility ratios for the disks were calculated and compared with accepted limit of ADA Specification No. 12 for acrylic resin

\section{RESULTS AND DISCUSSION}

The results of the transverse strength, tensile strength and surface hardness in this study were represented in Tables (1 and 2 ). The results showed that there was a highly significant difference between the fo- ur tested groups. The highest values were for the group IV while the lowest values were for group III.

The results showed that the values of the mechanical properties of the control Group I was lower than that of the control Group IV. The physical and mechanical properties of auto-polymerizing acrylic resin lower than that of the heat-polymerizing resin. ${ }^{(14)}$ The results appeared that the values of the mechanical properties of the Group II were higher than that of the Group I, the increasing of the values was significant for transverse strength and surface hardness but it was not for tensile strength, also these values still not reached the highest values of that of the Group IV, there were still a significant differences. So this give an indication that the epoxy resin provides toughness and other desirable properties to the acrylic resin. The results also showed that the values of the mechanical properties of the Group III were lower 
than that of the Group I, the differences were significant, that means it has an infer- ior mechanical properties than other three tested groups.

Table (1): analysis of variance for Transverse strength, Tensile strength and Surface hardness values of the tested groups.

\begin{tabular}{cccccccccc}
\hline \multirow{2}{*}{$\begin{array}{c}\text { Source of } \\
\text { variance }\end{array}$} & \multicolumn{2}{c}{ Transverse strength } & \multicolumn{3}{c}{ Tensile strength } & \multicolumn{2}{c}{ Surface hardness } \\
\cline { 2 - 10 } & df & MS & F-value & df & MS & F-value & df & MS & F-value \\
\hline $\begin{array}{c}\text { Groups of } \\
\text { materials used }\end{array}$ & 3 & 1981.228 & $* * 260000$ & 3 & 1394.667 & $* * 2440.67$ & 3 & $214.458 * * 343.13$ \\
Error & 28 & 0.008 & & 28 & 0.571 & & 27 & 0.625 \\
Total & 31 & & & 31 & & & 29 & \\
\hline
\end{tabular}

df: degree of freedom; MS: mean of sequare.

** Means are highly significant different at $\mathrm{P} \leq 0.01$

Table (2): Duncan Multiple Range test for Transverse strength, Tensile strength and Surface hardness values of the tested groups.

\begin{tabular}{|c|c|c|c|c|c|c|c|c|c|c|c|c|}
\hline \multirow[b]{2}{*}{$\begin{array}{l}\text { Groups of } \\
\text { materials } \\
\text { used }\end{array}$} & \multicolumn{4}{|c|}{$\begin{array}{c}\text { Transverse strength } \\
\left(\mathrm{N} / \mathrm{mm}^{2}\right)\end{array}$} & \multicolumn{4}{|c|}{$\begin{array}{l}\text { Tensile strength } \\
\text { ( Mpa ) }\end{array}$} & \multicolumn{4}{|c|}{ Surface hardness } \\
\hline & No & M & SD & 占 & No & $\mathbf{M}$ & SD & 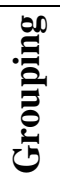 & No & M & SD & 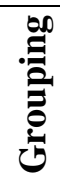 \\
\hline Group I. & 8 & 72.2 & 0.1195 & $\mathrm{~A}$ & 8 & 38 & 0.756 & $\mathrm{~A}$ & 8 & 87 & 0.756 & $\mathrm{~A}$ \\
\hline Group II & 8 & 81.075 & 0.07 & $\mathrm{C}$ & 8 & 40 & 0.756 & A & 8 & 90 & 0.756 & $\mathrm{C}$ \\
\hline Group III & 8 & 48.6 & 0.075 & $\mathrm{D}$ & 8 & 20 & 0.756 & $\mathrm{C}$ & 8 & 85.25 & 0.886 & $\mathrm{D}$ \\
\hline Group IV & 8 & 82.76 & 0.0744 & B & 8 & 52 & 0.756 & B & 8 & 97 & 0.756 & B \\
\hline
\end{tabular}

M: Mean; No: Number of samples; SD: Standard deviation; Group I: Control group (autocured acrylic resin alone); Group II: auto-cured acrylic resin mixed with $10 \%$ of its weight with epoxy resin; Group III: auto-cured acrylic resin mixed with $20 \%$ of its weight with epoxy resin; Group IV: Control group (heat-cured acrylic resin alone).

Means with different letters are significantly different.

The results of the water sorption and solubility tests are shown in Table (3). The results showed that the ratios were highest for group III and were out the accepted limit of ADA Specification No. 12. While, the ratios for the other groups were within the accepted limit. The results showed that the ratio of the water sorption of the Group I was higher than that of the Group IV, and the ratio of the Group II became the same as that of the Group IV, but the ratio of the Group III became higher than that of the Group I. This increasing of the water sorption will affect the properties of the resin. High uptake of water can soften a resin because the absorbed water can act as a plasticizer of the resin and reduce the strength of the material. ${ }^{(23,24)}$ The results appeared the ratio of the water solubility for the Group I wear higher than that of the Group
IV and this come in agreement with finding of Varpu and Vallittu ${ }^{(25)}$ in that because the monomer in chemical-cured PMMA is higher than in heat-cured PMMA, it should also solubility values. It has been suggested that there might be a correlation between residual monomer and the weight loss determined by the solubility test. Also the results appeared the ratios for the Group II were lower than that of the Group I, while the ratios for the Group III were higher than that of the Group I.

To explain the effect of the copolymerization process on the physical properties of the copolymerized (PMMA) acrylic resin, the chemical structures of the (PMMA) resin and epoxy resin should be discussed. 
Table (3): Ratios of water sorption and solubility of the tested groups

\begin{tabular}{cccc}
$\begin{array}{c}\text { Groups of tested } \\
\text { materials }\end{array}$ & No Water sorption after $\mathbf{7}$ days & $\begin{array}{c}\text { Water solubility after } \mathbf{7} \text { days } \\
\left(\mathbf{g m} / \mathbf{g m}^{\mathbf{2}} \mathbf{~}^{*}\right.\end{array}$ \\
\hline Group I & 2 & 0.6 & 0.04 \\
Group II & 2 & 0.55 & 0.03 \\
Group III & 2 & 0.8 & 0.07 \\
Group IV & 2 & 0.55 & 0.025 \\
\hline **ADA Sp. No. 12 & 2 & not more than 0.7 & not more than 0.04 \\
\hline
\end{tabular}

No: Number of samples; * : Mean; **ADA Sp. No.12: American Dental Association Specification Number 12 for acrylic resins ${ }^{(2)}$.

Combination of epoxy and acrylic offer interesting means of modifying both types of resins. Thus it was possible to bring about polymerization by mean of the convenient benzyl peroxide-tertiary amine curing systems commonly employed for the self curing acrylic resins. The reaction sites (oxirane groups) of the epoxy molecule were replaced by methacrylate group. In this way of hybrid molecule was produced that could be polymerized through the methacrylate group. Incorporation of a small number of epoxy groups in acrylic resins provides a convenient rout to thermosetting acrylics and makes available the whole gamut of epoxy resin curing agents as modifiers so epoxy resins may be used to provide cross-linking the acrylic resin molecules to increase hardness and heat stability. Cross-linkage strengthens the polymer and decreases its solubility also decreases the swelling ability of the re$\sin ^{(5,13,14)}$ This explain the improving of the mechanical properties and decreasing the ratios of water sorption and solubility of the auto-cured acrylic resin when copolymerized at $10 \%$.

The size of monomer and comonomer molecules, coupled with a rapid increase in viscosity during setting, causes relativeely high concentration of acrylate or methacrylate groups to remain unreacted after setting. ${ }^{(1)}$ The lower the degree of polymerization of a given solid polymer, the less will be its strength and stiffness. ${ }^{(5,14)}$ The epoxy resin is a viscous material at room temperature. ${ }^{(13,18)}$ So mixing ratio at $20 \%$ caused increasing in the viscosity of the mixed resins, later on caused high unreacted methacrylate groups, and high percentage of residual monomer, this explain why the mechanical properties of the autocured acrylic became worse and the water sorption and solubility ratios increased.

The improving of the mechanical properties and reinforcement of the auto-cured acrylic resin by a copolymerization process with epoxy resin at $10 \%$ may give the dentist a new option to treat patient with a less invasive FPD treatment and with somewhat lower cost than with traditional FPDs. The reinforced copolymerized auto-cured acrylic resin could be used in selected case of the conservative bridge which made by acid etching enamel and bonding a pontic to the adjacent natural teeth. Conservative tooth preparation is necessary to achieve optimal retention. ${ }^{(26-28)}$ In addition bonding of the teeth to auto-cured acrylic resin was increased by roughing the teeth surface and pre-wetting with swelling solvent in connection with methacrylate monomer probably improve the reliability of the join. ${ }^{(29)}$ The major advantages are conservation of natural tooth structure in circumstances when age (young), expensive, or clinical practically are considerations.

\section{CONCLUSION}

The physical properties of the temporary crowns and bridges auto-cured acrylic resin was improved and the resin was reinforced when copolymerized with $10 \%$ of its weight epoxy resin, but the values still not reached that of the heat-cured acrylic resin and they became worse when copolymerized with $20 \%$.

\section{REFERENCES}

1. McCabe JF. Anderson's Applied Dental 
Materials. $6^{\text {th }}$ ed. Blackwell Scientific Publications, London,UK. 1985; P: 153.

2. American Dental Association Specification. Guide to dental materials and device. $7^{\text {th }}$ ed. 1975; p: 205.

3. Vallittu PK. Flexural properties of acrylic resin polymers reinforced with unidirectional and woven glass fibers. $J$ Prosthet Dent. 1999; 81:318-326.

4. Van Nort R. Introduction to Dental Materials. $2^{\text {nd }}$ ed. Mosby Co. Missouri, USA. 2002; Pp: 96-124.

5. Skinner EW. Science of dental materials. $8^{\text {th }}$ ed. W.B. Saunder Co. Philadephia, USA. 1982; p: 202.

6. Eiichi N, Kenji O, Yoshinori S. Repair of denture base resin using woven metal and fiber: Effect of methylene chloride pretreatment. J Prosthet Dent. 2001; 85: 496-500.

7. Derrick LW, Daniel BB, Steven AA. Effect of polyethylene fiber reinforcement on the strength of denture base resins polymerized by microwave energy. $J$ Prosthet Dent. 1994; 72: 635-638.

8. Stafford GD, Bates JF, Huggett R. A review of some denture base polymer. J Dent. 1880; 8(4): 292-306.

9. Gregory L, Polyzois A, Mary J. Frangou. Fracture force, deflection at fracture, and toughness of repaired denture resin subjected to microwave polymerization or reinforced with wire or glass fiber. $J$ Prosthet Dent. 2001; 86: 613-619.

10. Salem AS. Reinforced denture base materials. Ph.d Thesis. Turner Dental School, University of Manchester. 1979

11. Craig RG, O'Brien WJ, Powers JM. Dental Materials. $6^{\text {th }}$ ed. Mosby Co. Missouri, USA. 1996; p: 244.

12. Vallittu PK. Effect of 180-weeks water storage on the flexural properties of E-glass and silica fiber acrylic resin composite. Int J Prosthodont. 2000; 13: 334-339.

13. Henry L, Kris N. Handbook of epoxy resin. $1^{\text {st }}$ ed. McGraw-Hill, Inc. California, USA. 1967; Pp: 17-18

14. Anusavice KJ. Philip's Science of Dental Materials. $10^{\text {th }}$ ed. W.B. Saunder Co. Philadephia, USA. 1996; Pp: 200-235.

15. Craig RG. Restorative Dental Materials. $10^{\text {th }}$ ed. Mosby Co. Missouri, USA. 1997; Pp: 500-546.

16. Chaffee NR, Bailey JH, Sherrard DJ. Dimensional accuracy of improved dental stone and epoxy resin die materials. Part I: single die. J Prosthet Dent. 1997; 77(2) : 131135.

17. Paquett. JM, Taniguchi T, White SN. Dimensional accuracy of an epoxy resin die material using two setting methods. J Porsthet Dent. 2000; 83 (3): 301-305.

18. Hart H. Organic chemistry. $7^{\text {th }}$ ed. Houghton Mifflin Co. Boston, USA. 1987; p: 223.

19. Mohammed MS. Evaluation of repairing the acrylic denture base by using different materials, designs, and techniques. MSc. Thesis. Collage of Dentistry. University of Mosul. 2004

20. Luma MA. Evaluation of some mechanical properties of reinforced acrylic resin denture base materials. MSc. Thesis. Collage of Dentistry. University of Mosul. 2005

21. Mitchell L, Mitchell DA. Oxford handbook of clinical dentistry. $3^{\text {rd }}$ ed. Oxford University Press. 1999; Pp:700-701.

22. Radhwan HH. Comparison of some physical properties of acrylic denture base material cured by water bath and microwave techniques. Al-Rafidain Dent J. 2003; 3(2): 143-147.

23. Widad A, Reta M, Abd Alwahid K. Filler reinforced acrylic denture base material. Part 2- Effect of water sorption on dimensional changes and transverse strength. $J$ Coll Dentistry. 2005; 17(1)6-10.

24. Varpu M, Vallittu PK. Water sorption and solubility of glass fiber-reinforced denture polymethyl methacrylate resin. $J$ Prosthet Dent. 1996; 76(5): 531-534.

25. Varpu M, Vallittu PK. Water sorption and solubility of glass fiber-reinforced denture polymethyl methacrylate resin. $J$ Prosthet Dent. 1996; 77(5): 531-534.

26. Theodore M, Harald O, Edward J. Art and Science of Operative Dentistry. $4^{\text {th }}$ ed. Mosby Co. Missouri, USA. 2002; Pp: 636638.

27. Stephen F, Martin F, Junhei F. Contemporary fixed prosthodontics. $2^{\mathrm{d}}$ ed. Mosby Co. Missouri, USA. 1995; Pp:548.

28. Vallittu PK, Camilla S. Resin-bonded, glass fiber-reinforced composite fixed partial dentures: A clinical study. J Prosthet Dent. 2000; 84: 413-418.

29. Aliaa WR. Evaluation of some mechanical and physical propertiesof relined acrylic denture base material by using different curing techniques. MSc. Thesis. Collage of Dentistry. University of Mosul. 2005. 